gou-nos a discorrer com mais detalhes o que consideramos objetivos do trabalho: diagnóstico clínico e os sinais das "faces do panda" mostrados pela ressonância magnética (RM). Assim sendo, pode-se compreender a maneira bastante resumida como foram descritos os fatos históricos e as medidas terapêuticas.

Em relação ao trabalho de Strümpell, não nos opomos à correção. Cumpre ressaltar que a citação do ano de 1898 baseou-se em McDowell et al. ${ }^{2}$ cujo texto referia: "In 1898 Strümpell reported 2 patients with tremor in whom liver disease was found at postmortem examination".

No que diz respeito à concentração normal de ceruloplasmina na doença de Wilson (DW) referida por Finelli, nossa intenção, de cunho puramente ilustrativo, foi mostrar mais um dado que pode dificultar o diagnóstico da doença, mas sem qualquer alusão histórica como, supomos, os senhores deduziram.

O paciente estudado por nós é portador de sintomatologia neurológica acentuada. O tratamento inicial com acetato de zinco não apresentou resposta satisfatória. A introdução da penicilamina, em substituição, provocou efeitos colaterais que motivaram sua suspensão após 40 dias de uso. Daí, a referência ao tetratiomolibdato, droga inexistente no mercado nacional, de ótima ação quelante e que não provoca piora do quadro neu rológico. As complicações hematológicas realmente existem mas podem ser revertidas com a suspensão do medicamento ${ }^{3}$. Ademais, supressão de medula óssea também faz parte dos efeitos adversos da penicilamina. Por outro lado, drogas não liberadas pela Food and Drug Administration (FDA) existem no mercado nacional e são de uso corrente como, por exemplo, a dipirona e a flunarizina. Certamente, estes esclarecimentos não significam que defendemos o uso do tetratiomolibdato no tratamento da DW, pois trata-se de uma droga que conhecemos apenas através da literatura.
Quanto aos achados da RM na DW, levantamos as seguintes considerações:

1) As imagens de hiperintensidade periférica em $T 2$ observadas no putâmen são, de fato, importantes mas não apresentam especificidade e podem ser encontradas na região central do núcleo ${ }^{4}$ ou difusamente ${ }^{5}$;

2) O sinal da "face do panda" é considerado característico da DW4 e sua baixa freqüência não está devidamente estudada, haja vista tratar-se de imagem radiológica divulgada pela primeira vez em $1991^{4}$ e somente 9 anos depois re gis trourse outro relato ${ }^{6}$. Esta lacuna temporal pode depender, portanto, de vários fatores como baixa freqüência, desconhecimento da existência do sinal ou mesmo pelo desaparecimento da imagem durante o tratamento. Ademais, o nosso trabalho registra o primeiro caso da literatura nacional, fato que consideramos relevante e que motivou o envio para publicação;

3) Finalmente, consideramos ainda que o diagnóstico da DW baseia-se, sobretudo, na sintomatologia, nas alterações da ceruloplasmina e do cobre e na evidência do anel de Kayser-Fleischer.

\section{REFERÊNCIAS}

1. Brito JCF, Coutinho MAP, Almeida HJF, Nóbrega PV. Doença de Wilson: diagnóstico clínico e sinais das "faces do panda" à ressonância magnética. Relato de caso. Arq Neuropsiquiatr 2005;63:176-179.

2. McDowell FH, Lee JE, Sweet RD. Extrapiramidal disease. In Baker AB (ed). Clinical neurology. Philadelphia: Harper \& Row, 1978; 38: 1-67

3. Brewer GS. Wilson's disease. Curr Treat Opt Neurol 2000;2:193-203.

4. Hitoshi S, Makoto I, Yoshikava K. Mid-brain pathology of Wilson's disease: MRI analysis of three cases. J Neurol Neurosurg Psychiatry 1991; 54:624-626.

5. Neto M Jr. Doenças da substância branca e dos núcleos da base. In Magalhães ACA. Ressonância magnética do sistema nervoso central. São Paulo: Editora Atheneu, 1999: 125-150.

6. Kuruvilla A, Joseph S. "Face of giant panda" sign in Wilson's disease: revisited. Neurol India 2000;48:395-396.

José Correia de Farias Brito Paulo Virgolino da Nóbrega

\title{
DEMÊNCIA SEMÂNTICA
}

Ao Editor - Como é minha rotina, li com atenção os artigos dos Arquivos de Junho de 2005, entre eles “Demência semântica: avaliação clínica e de imagem. Relato de caso. Arq Neuropsiquiatr 2005;63:348-352", de L. Caixeta e L.L. Mansur.

Eu gostaria de cumprimentar os autores pela qualidade da apresentação do caso, e, respeitosamente, sugerir que sua afirmativa de que não existem "casos autóctones" seja corrigida. Nós publicamos um caso semelhante há 16 anos, nos primórdios internacionais dos conceitos sobredemências frontais, quando ainda se discutiam os limites exatos de doença de Alzheimer (Oliveira SAV, Cast roMJMO, Bittencourt PRM. Slowly prog ressive aphasia followed by Alzheimer's dementia: a case report. Arq Neuropsiquiatr 1989;47:72-75). O caso era autóctone: o paciente pertencia a uma tradicional família brasileira. Da mesma maneira, a afirmação sobre o "relativo desco- nhecimento desta forma de demência no Brasil", precisa ser revista.

Imagino que nosso artigo não tenha sido revisado pelos autores pela sua antigüidade. Pode até ser um elogio indireto, que nossa publicação tenha sido muito precoce para um artigo nacional: seria o quarto mais antigo da revisão bibliográfica dos autores, publicado 7 anos após a descrição original de Marcel Mesulam. Segundo discussão em recente congresso brasileiro de neurologia, após uma mesa redonda sobre demências f rontotemporais (Nitrini R, comunicação pessoal, 2002), nossa publicação fez a primeira menção à doença de Alzheimer na literatura neurológica brasileira. Portanto, faz parte da história dos estudos das demências no Brasil. É claro, passou mesmo crivo editorial que o artigo de Caixeta e Mansur.

$\mathrm{O}$ artigo original contém uma tomografia computa- 
dorizada que exemplifica o mesmo achado que o artigo recente descreve com uma imagem de ressonância magnética. Esta é a contribuição da descrição de caso de Caixeta e Mansur.

Paulo R.M. de Bittencourt

Membro Titular da Academia Brasileira de Neurologia, 1982 Fellow da American Academy of Neurology, 1991

Resposta dos Autores - Agradecemos o interesse demonstrado, bem como os elogios exarados pelo Dr. Paulo Bittencourt, referentes ao nosso artigo sobre demência semântica, publicado em junho nos Arquivos de Neuro-Psiquiatria. O colega sugere, entretanto, que seja revista a caracterização do caso como sendo o primeirode um paciente brasileiro portador de demência semântica relatado na literatura científica, posto que defende seu pioneirismo neste assunto ao publicar em co-autoria um caso de afasia lentamente progressiva em 1989'. Sugere ainda a revisão do comentário que fizemos sobre o "relativo desconhecimento desta forma de demência no Brasil".

Quanto à primeira questão, devemos dizer que o excelente artigo de Oliveira et al. ${ }^{1}$ foi pioneiro na caracterização de um caso brasileiro de afasia lentamente prog ressiva (provavelmente da forma não-fluente), mas não de demência semântica. Os conceitos de demência semântica (nosso caso) e afasia lentamente progressiva (caso do Dr. Paulo Bittencourt) são diferentes, ainda que guardem algumas semelhanças clínicas e possam, em alguns casos, compartilhar a mesma histopatologia. Neste sentido, diga-se de passagem, fizemos breve histórico em nosso artigo das divergências existentes na a bo ordagem nosográfica destas entidades clínicas. É assim que, dentro da perspectiva de Marcel Mesulan² ${ }^{2}$ a afasia prog ressiva primária-APP (mais precisamente o subgrupo de pacientes com afasia tipo fluente) englobaria a demência semântica (denominação que, inclusive, rejeita), opinião contestada por Julie Snowden ${ }^{3}$, para quem os casos de Mesulan se referem a uma outra entidade nosológica diferente da demência semântica. De fato, existem muitas diferenças mesmo quando comparamos a formafluente da APP com a demência semântica. Nesta última condição, o comprometimento da cognição parece mais prevalente (quando comparado à forma fluente da APP), afetando o reconhecimento de palavras e objetos, associados à prosopagnosia, características geralmente relacionadas à disfunção temporal bilateral ${ }^{4,5}$. Acrescese o fato de que a discalculia, freqüente na $A^{2} P^{2}$, não está presente na demência semântica até as fases tardias da doença ${ }^{3}$. Diferentemente do que o Dr. Paulo Bittencourt afirma, a tomografia computadorizada de crânio
(TCC) que ilustra seu artigo não descreve o mesmo achado da ressonância magnética (RM) de nosso paciente. A TCC de seu paciente ilustra um achado típico da APP (e não da demência semântica): atrofia mais marcante na região perisylviana esquerda. Já a RM de nosso paciente é clássica da demência semântica: atrofia bitemporal assimétrica. Sutis diferenças que re presentam muito para um diagnóstico diferencial. Também não consideramos correta a afirmação de que a RM foi a única contribuição do caso, posto que apresentamos estudo de neuroimagem funcional (SPECT), além de cuidadosa avaliação neuropsicológica e avaliação de linguagem específica para distúrbios semânticos, bem como discutimos a posição desta forma de demência no contexto do grupo das degenerações lobares frontotemporais, elementos que não fizeram parte do artigo de Oliveira et al. Por último, ainda quanto à ausência de artigos sobre casos autóctones no Brasil, fizemos levantamento no Medline com a palavra-chave 'Semantic Dementia' e não encontramos casos brasileiros desta condição até a data de envio do artigo para esta revista.

Quanto à segunda questão, nossa defesa de que a demência semântica constitui ainda uma ilustre desconhecida na maior parte da classe médica no Brasil, não deveria causar estranheza se considerarmos a origem recente deste constructo diagnóstico, o qual remonta à década de 1980. Nossa afirmação foi embasada em nossa experiência de divulgação deste grupo de demências e em enquête que temos feito ao redor do país sobre o tema. Todos os casos acumulados até o momento foram-nos encaminhados com o diagnóstico equivocado de doença de Alzheimer (caso, inclusive, do paciente relatado no artigo). É óbvio, entretanto, que a situação dos núcleos universitários e outros centros de excelência é diferente, onde existe constante difusão de novos conhecimentos, atualização e reciclagem de seus membros, oportunidades ainda raras se considerarmos a realidade da maior parte dos médicos no Brasil.

\section{REFERÊNCIAS}

1. Oliveira SAV, Castro MJMO, Bittencourt PRM. Slowly progressive aphasia followed by Alzheimer`s dementia: a case report. Arq Neuropsiquiatr 1989;47:72-75.

2. Mesulan MM. Principles of behavioral and cognitive neurology. Oxford: Oxford University Press, 2000: 455-458.

3. Snowden JS, Neary D, Mann DMA. Fronto-temporal degeneration: f ronto-temporal dementia, progressive aphasia, semantic dementia. London: Churchill Livingstone, 1996: 91-114.

4. Hodges JR, Garrard P, Patterson K. Semantic dementia. In Kertesz A, Munoz DG. (eds). Pick's disease and Pick complex. Wiley-Liss, 1998: 83-103.

5. Snowden JS, Griffiths HL, Neary D. Progressive language disorder associated with frontal lobe degeneration. Neurocare 1996;2:429-440.

Leonardo Caixeta 